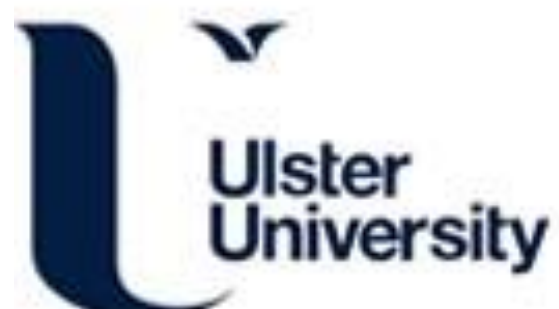

Validation of the Pittsburgh Sleep Quality Index (PSQI) with Arabic cancer patients

Al Maqbali, M., Hughes, C., Gracey, J., Jane Rankin, Dunwoody, L., \& Eileen Hacker (2020). Validation of the Pittsburgh Sleep Quality Index (PSQI) with Arabic cancer patients. Sleep and Biological Rhythms, 18(3), 217223. https://doi.org/10.1007/s41105-020-00258-w

Link to publication record in Ulster University Research Portal

Published in:

Sleep and Biological Rhythms

Publication Status:

Published (in print/issue): 01/07/2020

DOI:

10.1007/s41105-020-00258-w

Document Version

Author Accepted version

\section{General rights}

Copyright for the publications made accessible via Ulster University's Research Portal is retained by the author(s) and / or other copyright owners and it is a condition of accessing these publications that users recognise and abide by the legal requirements associated with these rights.

\section{Take down policy}

The Research Portal is Ulster University's institutional repository that provides access to Ulster's research outputs. Every effort has been made to ensure that content in the Research Portal does not infringe any person's rights, or applicable UK laws. If you discover content in the Research Portal that you believe breaches copyright or violates any law, please contact pure-support@ulster.ac.uk. 


\section{Title Page}

\section{Validation of the Pittsburgh Sleep Quality Index (PSQI) with Arabic Cancer Patients}

Authors

\begin{tabular}{|l|l|l|l|l|}
\hline No & \multicolumn{1}{|c|}{ Author } & \multicolumn{1}{|c|}{ Credentials } & \multicolumn{1}{|c|}{ Titles } & \multicolumn{1}{c|}{ Author affiliations } \\
\hline 1 & $\begin{array}{l}\text { Mohammed } \\
\text { Al Maqbali }\end{array}$ & $\begin{array}{l}\text { RN., Dip. } \\
\text { Admin., B.Sc. } \\
\text { (Hons)., M.Sc., } \\
\text { PhD }\end{array}$ & Researcher & $\begin{array}{l}\text { Institute of Nursing and Health Research, } \\
\text { Ulster University, Newtownabbey, UK }\end{array}$ \\
\hline 2 & Ciara Hughes & PhD & $\begin{array}{l}\text { Senior Lecturer, School of } \\
\text { Health Sciences }\end{array}$ & $\begin{array}{l}\text { Institute of Nursing and Health Research, } \\
\text { Ulster University, Newtownabbey, UK }\end{array}$ \\
\hline 4 & Jackie Gracey & $\begin{array}{l}\text { (Hons) } \\
\text { Physiotherapy }\end{array}$ & $\begin{array}{l}\text { Lecturer, School of Health } \\
\text { Sciences }\end{array}$ & $\begin{array}{l}\text { Institute of Nursing and Health Research, } \\
\text { Ulster University, Newtownabbey, UK }\end{array}$ \\
\hline 5 & $\begin{array}{l}\text { Lynn } \\
\text { Dunwoody } \\
\text { M.Sc. (Hons), }\end{array}$ & $\begin{array}{l}\text { PhD, AFBPsS, } \\
\text { C.Psychol, } \\
\text { FHEA }\end{array}$ & $\begin{array}{l}\text { Physiotherapy Clinical Lead } \\
\text { Lecturer in Health Psychology }\end{array}$ & $\begin{array}{l}\text { Physiotherapy Department, Cancer } \\
\text { Centre, Belfast Health and Social Care } \\
\text { Trust, Belfast, UK }\end{array}$ \\
\hline University, Coleraine, UK \\
\hline
\end{tabular}

Corresponding Author:

Mohammed Al Maqbali, PhD

Shore Road, Jordanstown Campus

BT37 0QB Newtownabbey

United Kingdom

Phone+442890368355

E-mail: Al_Maqbali-MA@ulster.ac.uk

Running Title: Validation of Arabic PSQI version

\begin{tabular}{|l|c|}
\hline Text word count & 2779 \\
\hline Tables & 3 \\
\hline Figure & 2 \\
\hline References & 36 \\
\hline
\end{tabular}




\title{
Validation of the Pittsburgh Sleep Quality Index (PSQI) with Arabic Cancer \\ Patients
}

\begin{abstract}
:
Introduction

The Pittsburgh Sleep Quality Index (PSQI), a self-administrated questionnaire, is a frequently used instrument to assess sleep quality in clinical and non-clinical populations. The aim of the study was to evaluate the psychometric properties of the Arabic PSQI among patients diagnosed with cancer.
\end{abstract}

\section{Methods}

A cross-sectional and descriptive correlational design was used with 369 patients with cancer completing the 19-item Arabic version of the PSQI. The scale was assessed in terms of acceptability, internal consistency and validity.

\section{Results}

The Cronbach's alpha coefficient for the Arabic PSQI was 0.77, demonstrating acceptable reliability. The global PSQI score did not have floor or ceiling effects. The PSQI Arabic version demonstrated good discriminative validity. Construct validity was explored by confirmatory factor analysis to examine the dimensional structure of the PSQI. The confirmatory factor analysis showed an acceptable fit for refined one-factor model. The results support the original single factor structure of the PSQI.

\section{Conclusions}

The Arabic version of the PSQI demonstrated adequate reliability and validity for assessing sleep quality in Arabic-speaking patients diagnosed with cancer.

Keyword's: PSQI; Validity; Reliability; Arabic; Cancer; CFA 


\section{Introduction:}

Patients diagnosed with cancer often experience sleep disturbance in the form of poor sleep patterns or insomnia, which can start on diagnosis and continue until the end of the individual's life $[1,2]$. It is estimated that sleep disturbance affects $50-75 \%$ of cancer patients $[3,4]$. Sleep disturbance in cancer patients can have a negative impact on their quality of life (QoL), which includes their physical and psychological functioning [5,6]. In addition, sleep disturbance has been associated with cancer recurrence [7,8], and may result in poor healing [9], cognitive dysfunction [10] and reduced work activity [11].

One of the most widely used instruments that measures sleep quality in both clinical and nonclinical populations is the Pittsburgh Sleep Quality Index (PSQI) [12]. The scale is easy to understand, can be completed within 5 to 10 minutes, and contains 19-items that are combined into seven subscales: subjective sleep quality, sleep latency, sleep duration, habitual sleep efficiency, sleep disturbances, use of sleep medications and daytime dysfunction. The original PSQI was used to assess sleep quality in three groups: a healthy sample, patients with depression, and those with sleep disorders. The instrument exhibited good validity and test-retest reliability [12].

The PSQI has been used across a variety of clinical populations, such as those with diabetes [13], dementia [14], fibromyalgia [15] and cancer [16]. Mollayeva et al. [17] undertook a systematic review of 37 articles that evaluated the weighted mean difference of the PSQI for clinical and nonclinical samples. The review found that the PSQI's mean global score was significantly higher in clinical samples compared to non-clinical ones.

The PSQI has been translated into different languages and cultures, including Greek [18], German [19], Chinese [20] and Spanish [15], all versions exhibited adequate psychometric properties. In addition, the PSQI has been translated and validated with an Arabic sample living in the United 
States [21]. However, whilst it is acknowledged that Arabic countries share a common language with this American sample, there may be cultural differences that need to be taken into consideration. In addition, the American-Arabic version of the PSQI was tested in a non-clinical sample [21].

To the best of our knowledge, the PSQI has not been validated in cancer, clinical populations in Arabic countries [22]. Therefore, the aim of this study was to examine the validity and reliability of the Arabic PSQI with a heterogeneous sample of cancer patients who have completed surgical intervention, chemotherapy and/or radiotherapy treatment. Validation of the Arabic PSQI in an Arabic country will provide a suitable and acceptable cultural fit instrument for the screening and assessment of sleep disturbance in clinical practice. The original PSQI was specified as a single factor model [12]. In cancer populations, it has been found that the one-factor model fits the PSQI global score [23], whereas Otte et al. [24] have suggested a two-factor model. Therefore, a one factor and two-factor model were examined in this study.

\section{Methods:}

\section{Participants:}

A cross-sectional survey was used and participants were recruited from the National Oncology Centres outpatient clinic in Oman. Data was collected from November 2018 to January 2019. Inclusion criteria for participation were as follows: adult patients over 18 years of age, able to speak and write in Arabic, no known psychiatric or neurological disorders that could interfere with study participation, a diagnosis of any type of cancer and completion of surgical intervention, chemotherapy and/or radiotherapy treatment at least one month prior to recruitment. Participants were excluded if they were undergoing chemotherapy or radiotherapy treatment or were newly diagnosed cancer patients awaiting surgery. 
Ethical permission was sought from the Research and Ethical Review and Approval Committee in the Directorate General of Planning and Studies at the Ministry of Health, Oman.

\section{Instrument:}

The PSQI is a self-completed questionnaire that assesses sleep quality over the previous month [12]. The scale has 19-items, five of which should be answered by bed mates or roommates. These five are not calculated in the global score of the PSQI, but rather are only used as clinical information. They were not included in this study. The 19-items are categorised into seven components: subjective sleep quality, sleep latency, sleep duration, habitual sleep efficiency, sleep disturbances, use of sleep medications and daytime dysfunction. The scores of each of the seven components range from 0 to 3 and a global score can be calculated by summing the seven components, giving a range from 0 to 21 ; higher scores indicate poor sleep quality. Buysse et al. [12] suggested that those with global scores of more than five should be classified as poor sleepers: those with scores of less than or equal to five should be classified as good sleepers. Demographic data was collected on age, gender, educational level, marital status, employment status, type of cancer, stage, type of treatment undergone and time since diagnosis.

\section{Translation of PSQI}

The PSQI Arabic version was translated and validated by Suleiman et al. [21] in a sample of healthy Arab Americans. To ensure the applicability of the instrument, in the current study, the PSQI Arabic version was compared with the original English version by two independent and bilingual translators, both of whom were aware of the study objective. This procedure was to ensure that the scales were translated into Modern Standard Arabic, which is employed for official use in all Arabic countries. 
In order to examine the clarity and comprehensibility of the PSQI Arabic version in this study, a pilot study was carried out with ten patients diagnosed with cancer. This highlighted some difficulties regarding the layout of the questionnaire. Accordingly, the structure of the PSQI Arabic version was amended: all the questions were placed in a table so they were easy to identify and would not be missed by participants.

\section{Statistical Analyses:}

Data were analysed using the Statistical Package for the Social Sciences (SPSS) 25.0. The internal consistency of the PSQI was evaluated using Cronbach's alpha coefficient for each subscale and the overall scale, with an alpha of 0.70 or higher considered as acceptable [25]. Floor and ceiling effects were calculated by the number of individuals in the total sample who achieved the lowest or highest levels of the scores in the scales; these were deemed of importance if more than $15 \%$ of the respondents achieved the lowest or highest possible scores [26].

Discriminative validity of the PSQI evaluated the ability of the scale to differentiate defined groups according to patient demographic and clinical characteristics. One-way analysis of variance (ANOVA) and independent sample t-tests were used to test the differences in the PSQI's mean scores between gender, cancer site and comorbidities.

Construct validity was tested with Confirmatory Factor Analysis (CFA). The PSQI was originally specified as a single factor model, which was proposed as a unidimensional structure [12]. In cancer populations, Ho and Fong [23] and Fontes et al. [27] provided supported for the one-factor model, however, Otte et al. [24] have suggested that a two-factor model is the best fit in breast cancer populations. Therefore, CFA was conducted using AMOS 25 to exam the fit statistics of the two models. The one-factor model, as given by the original publication [12], included all seven components. In the two-factor model as Otte et al.[24] suggested, the first factor encompassed 
sleep quality to include subjective sleep quality, sleep latency, sleep disturbances, use of sleep medication and daytime dysfunction. The second factor encompassed sleep efficiency and included sleep duration and habitual sleep efficiency.

The following criteria were used to evaluate the model fit according to Hair et al. [28]; nonsignificance of chi-square $\left(\chi^{2}-\right.$ test); chi-square per degree of freedom $\left(\chi^{2} / d f\right)$ of less than 3 ; root mean square error of approximation (RMSEA) of less than or equal to 0.08 ; comparative fit index (CFI) greater than 0.95; the goodness of fit index (GFI) and adjusted goodness of fit index (AGFI) of more than or equal to 0.90 to indicate good fit; and the Tucker-Lewis index (TLI) greater than 0.90 .

\section{Results:}

Of the 400 patients eligible to participate, 369 completed and returned valid questionnaire booklets, giving a response rate of $92.2 \%$. The demographic and clinical characteristics of the participants are presented in table 1. The majority of participants were female $(66.4 \%)$ and three quarters were married (74\%). Over 55\% of the participants completed secondary level of education or held a degree. Approximately $37 \%$ of the participants were diagnosed with breast cancer and $14 \%$ with colorectal cancer. The global PSQI scores ranged from 2-19 with a mean of 9.22 (SD 4.21). Using the cut off criteria of total PSQI score of more than five, as suggested by Buysse et al. [12], 288 (78\%) participants were identified as poor sleepers.

\section{Factorial validity:}

A one-factor model was tested $\left(\chi^{2}(\mathrm{df}=14)=178.035, \mathrm{P}<.001, \mathrm{GFI}=0.88, \mathrm{AGFI}=0.76, \mathrm{CFI}=0.76\right.$, $\mathrm{TLI}=.65$, RMSEA $=0.18$. and $\chi^{2} / \mathrm{df}=12.71$, which indicated the poor fit of the model. Based on the modification indices, a path of covariance was then added between error terms for component three (sleep duration) and component four (habitual sleep efficiency). The refined one-factor 
model fit indices of the sample were $\chi^{2}(\mathrm{df}=13)=35.18, \mathrm{P}<.001, \mathrm{GFI}=0.97, \mathrm{AGFI}=0.94, \mathrm{CFI}=0.97$, $\mathrm{TLI}=.95 \mathrm{RMSEA}=0.06$ and $\chi^{2} / \mathrm{df}=2.7$, which indicates an acceptable fit for the data (Figure 1). The two-factor model performed better fit $\left(\chi^{2}(\mathrm{df}=13)=35.18, \mathrm{P}<.001\right.$, GFI=0.97, AGFI=0.94, $\mathrm{CFI}=0.97, \mathrm{TLI}=.95, \mathrm{RMSEA}=0.06$. and $\left.\chi^{2} / \mathrm{df}=2.7\right)($ Figure 2$)$, which shows a similar acceptance of fitness indices of the refined one-factor model.

\section{Reliability:}

The global PSQI score did not exhibit floor or ceiling effects for the Arabic cancer patients; none of the participants had the lowest possible score of 0 or the highest possible score of 21 . However, some of the seven components did demonstrate floor and ceiling effects. Ceiling effects were observed in subjective sleep quality, sleep latency, sleep duration and habitual sleep efficiency; more than $15 \%$ of participants achieved the highest score. Floor effects were apparent in the use of sleep medication and daytime dysfunction, as more than $15 \%$ of the respondents achieved the lowest score.

Internal consistency was assessed using Cronbach's alpha. The PSQI Arabic version score was 0.77, which was considered to be acceptable. All seven components appeared to measure a particular aspect of the PSQI. The largest component-total correlation coefficient was found for subjective sleep quality (0.62), whereas the smallest was found for sleep disturbances $(0.38)$. The items' total correlations and Cronbach's alpha if item deleted of the seven components and total score compared with the original validation of the PSQI (Table 2).

\section{Discriminative validity:}

Differences between the mean of the global PSQI according to the gender, cancer site, cancer stage and comorbidities are shown in table 3. The mean of the global PSQI was highest among patients with comorbidities compared to patients without $(\mathrm{p}<0.001)$. Gender showed no statistically 
significant differences on PSQI global score $(\mathrm{p}=0.53)$. Patients with lung $(\mathrm{M}=12.95 \mathrm{SD}=3.53)$, gastrointestinal $(\mathrm{M}=12.05 \mathrm{SD}=3.96)$ and brain $(\mathrm{M}=11.84 \mathrm{SD}=4.89)$, cancer had significant differences in reporting the higher mean scores on global PSQI $(\mathrm{p}<0.001)$. The global PSQI was able to discriminate between cancer stages $(\mathrm{p}=0.006)$. Post hoc analyses using Turkey's HSD indicated that cancer stage four had higher mean global scores $(M=10.69 \mathrm{SD}=4.29)$ than other cancer stages. This indicated that the PSQI Arabic scale has discrimination validity.

\section{Discussion:}

Assessment of sleep problems for Arabic cancer patients is necessary, however, a valid and reliable sleep instrument is needed to support clinical decision making for interventions that can improve sleep. To our knowledge, this is the first study to examine the psychometric properties of the PSQI in patients diagnosed with cancer in Arabic populations. This study demonstrated that the Arabic version of the PSQI tested in a cancer population demonstrates adequate reliability as well as discriminative and construct validity. Confirmatory factor analysis supported a one factor and two factor model, although the one-factor model performed best. Although PSQI components had floor or ceiling effects, the global PSQI score did not show either floor or ceiling effects. This indicates that the item analysis supported the content validity of the overall score of the scale [26].

The study found the prevalence of poor sleepers (PSQI >5) was 78\%, which is higher than findings by George et al. [29] who reported poor sleeper as 64\%, but consistent with Wu et al.[30], who reported $77.3 \%$ of poor sleeper in cancer survivors.

There was an acceptable degree of internal consistency between the total score of the Arabic version of the PSQI and the seven components: Cronbach's alpha was 0.77, which was considered to be acceptable. All seven components appeared to measure a particular aspect of the PSQI. Previous studies have reported similar results in cancer populations [16,27,31]. Mollayeva et al. 
[17] conducted a systematic review of 37 studies that evaluated the measurement properties; they found Cronbach's alpha to be between 0.70 and 0.83 . The original internal consistency proposed by Buysse et al. [12] was 0.83. The Arabic version of the PSQI in non-clinical populations reported an alpha reliability of 0.65 [21]. Thus, the findings related to internal consistency from this study were consistent with the published literature.

Adequate items' total correlations provided further support for internal reliability consistency. Six components of the PSQI reported the items' total correlation coefficients levels between 0.66 (subjective sleep quality) and 0.42 (habitual sleep efficiency). Only sleep disturbance components had 0.38 (Table 2). This indicates that Arabic PSQI had good internal consistency. Similarly, Buysse et al. [12] have reported that the item total correlation of sleep disturbance was 0.35 . The sleep disturbance component was answered by nine questions, which could result in variations between participants [12]. The items' total correlation needed to be above 0.3 , which was set as the minimum level [25].

The PSQI appeared to be capable of discriminating between groups that differed in cancer site, prognosis and comorbidities. Similar discriminative validity has been noted in psychometrics studies among patients with cancer [16,18].

The current study found that a refined one-factor model showed acceptable fit with the residual covariance between component three (sleep duration) and component four (habitual sleep efficiency); this can be explained as these two components were answered in the PSQI by question one, 'usual bed time at night', question three, 'usual getting up time in morning,' and question four, 'hours of sleep per night' as both components were derived from the same questions. In this study, the participants might have miscalculated both sleep duration and sleep efficiency. Several studies have reported low accuracy or difficulty for participants to determine the time of falling 
asleep [32,33]. In accordance with previous studies, this correlation was found between component three (sleep duration) and component four (habitual sleep efficiency) [23,24,27,34,35].

None of the refined one and two-factor model structures had absolute fit as chi-square $\left(\chi^{2}\right)$ had significant p-value. Despite this, both the refined one and two-factor models had few cut-offs of the fit indices in GFI, AGFI, CFI and RMR, which indicted an acceptable fit. Three studies have investigated the CFA of the PSQI among cancer patients and found similar results to the present study, but their conclusions were different. Otte et al. [24] suggested that a two-factor model was a better fit than the one-factor model of the original PSQI. Whereas two other studies supported the one-factor model of the original PSQI $[23,27]$. This study supports the original single factor structure of the PSQI that Buysse et al. [12] proposed.

There are several limitations in this study. The study employed a cross-sectional design. The stability of the instrument was not reported using test-retest reliability, therefore further assessment of test-retest reliability is needed. This study did not test the concurrent validity, further research study should assess sleep quality by PSQI and another self-reported tools such as Insomnia Severity Index (ISI) [36] to identify the correlations between them. In addition, the study did not have control groups of non-cancer samples who also complain of sleep disorders. The data were collected after treatment was completed and so the results are not generalizable to patients currently receiving treatment.

The findings demonstrate that the Arabic version of the PSQI demonstrates acceptable psychometric properties in cancer patients and that it can be used to measure sleep quality. The current results support the view that the PSQI is best represented as being a unidimensional scale in an Arabic sample. 


\section{Conclusion:}

Arabic patients with cancer may affected by sleep disturbance, during or after treatment of cancer. A validated tool to assess sleep disturbance is needed to address the sleep problem in Arabic patient with cancer. This study found that Arabic version of the PSQI has acceptable psychometric properties of internal consistency reliability as well as discriminative and construct validity. Therefore, the Arabic version of the PSQI is a reliable and validated instrument to assess sleep quality in Arabic cancer populations. Further research on the Arabic version should evaluate testretest reliability. 
Authors' contributions: Al Maqbali completed the data collection, statistical support, and provided analysis. All authors contributed to the conceptualization and design and the manuscript preparation.

Acknowledgement: This study was conducted as part of a $\mathrm{PhD}$ thesis, which was funded by the Ulster University Vice-Chancellor's Research Scholarship.

\section{Compliance with Ethical Standards}

Conflicts of interest: The authors certify that there is no actual or potential conflict of interest in relation to this article.

Ethical approval: Ethical review was initially provided by the Nursing and Health Research Institute Filter Committee at Ulster University (No: 17/0050). The study was approved by the Research and Ethical Review and Approval Committee in the Directorate General of Planning and Studies at the Ministry of Health (MoH/DGPS/CSP/PROPOSAL_ APPROVED/31/2017) and conducted in accordance with the Declaration of Helsinki.

Informed consent: Informed consent was obtained from all participants included in the study. 


\section{References:}

1. Berger AM. Update on the State of the Science: Sleep-Wake Disturbances in Adult Patients With Cancer. Oncol Nurs Forum. 2009;36:E165-77.

2. Otte JL, Carpenter JS, Russell KM, Bigatti S, Champion VL. Prevalence, Severity, and Correlates of Sleep-Wake Disturbances in Long-Term Breast Cancer Survivors. J Pain Symptom Manage. 2010;39:535-47.

3. Ancoli-Israel S. Sleep Disturbances in Cancer: A Review. Sleep Med Res. 2015;6:45-9.

4. Berger AM, Parker KP, Young-McCaughan S, Mallory GA, Barsevick AM, Beck SL, et al. Sleep wake disturbances in people with cancer and their caregivers: state of the science. Oncol Nurs Forum. 2005;32:E98-126.

5. Palesh OG, Roscoe JA, Mustian KM, Roth T, Savard J, Ancoli-Israel S, et al. Prevalence, demographics, and psychological associations of sleep disruption in patients with cancer: University of Rochester Cancer Center-Community Clinical Oncology Program. J Clin Oncol. 2010;28:292-8.

6. Rolke HB, Bakke PS, Gallefoss F. HRQoL changes, mood disorders and satisfaction after treatment in an unselected population of patients with lung cancer. Clin Respir J. 2010;4:168-75.

7. Sigurdardottir LG, Valdimarsdottir UA, Mucci LA, Fall K, Rider JR, Schernhammer E, et al. Sleep Disruption Among Older Men and Risk of Prostate Cancer. Cancer Epidemiol Biomarkers Prev. 2013;22:872-9.

8. Thompson CL, Li L. Association of Sleep Duration and Breast Cancer OncotypeDX Recurrence Score. Breast Cancer Res Treat. 2012;134:1291-5.

9. Otte JL, Carpenter JS, Manchanda S, Rand KL, Skaar TC, Weaver M, et al. Systematic review of sleep disorders in cancer patients: can the prevalence of sleep disorders be ascertained? Cancer Med. 2015;4:183-200.

10. Schagen SB, Klein M, Reijneveld JC, Brain E, Deprez S, Joly F, et al. Monitoring and optimising cognitive function in cancer patients: Present knowledge and future directions. Eur J Cancer Suppl. 2014;12:29-40.

11. Die Trill M. Anxiety and sleep disorders in cancer patients. Eur J Cancer Suppl. 2013;11:21624.

12. Buysse DJ, Reynolds CF, Monk TH, Berman SR, Kupfer DJ. The Pittsburgh Sleep Quality Index: a new instrument for psychiatric practice and research. Psychiatry Res. 1989;28:193-213.

13. Zhu B, Xie M, Park CG, Kapella MC. Adaptation of the Pittsburgh Sleep Quality Index in Chinese adults with type 2 diabetes. J Chin Med Assoc. 2018;81:242-7. 
14. Curcio G, Tempesta D, Scarlata S, Marzano C, Moroni F, Rossini PM, et al. Validity of the Italian Version of the Pittsburgh Sleep Quality Index (PSQI). Neurol Sci. 2013;34:511-9.

15. Hita-Contreras F, Martínez-López E, Latorre-Román PA, Garrido F, Santos MA, MartínezAmat A. Reliability and validity of the Spanish version of the Pittsburgh Sleep Quality Index (PSQI) in patients with fibromyalgia. Rheumatol Int. 2014;34:929-36.

16. Beck SL, Schwartz AL, Towsley G, Dudley W, Barsevick A. Psychometric evaluation of the Pittsburgh sleep quality index in cancer patients. J Pain Symptom Manage. 2004;27:140-8.

17. Mollayeva T, Thurairajah P, Burton K, Mollayeva S, Shapiro CM, Colantonio A. The Pittsburgh sleep quality index as a screening tool for sleep dysfunction in clinical and non-clinical samples: A systematic review and meta-analysis. Sleep Med Rev. 2016;25:52-73.

18. Kotronoulas GC, Papadopoulou CN, Papapetrou A, Patiraki E. Psychometric evaluation and feasibility of the Greek Pittsburgh Sleep Quality Index (GR-PSQI) in patients with cancer receiving chemotherapy. Support Care Cancer. 2011;19:1831-40.

19. Hinz A, Glaesmer H, Brähler E, Löffler M, Engel C, Enzenbach C, et al. Sleep quality in the general population: psychometric properties of the Pittsburgh Sleep Quality Index, derived from a German community sample of 9284 people. Sleep Med. 2017;30:57-63.

20. Tsai P-S, Wang S-Y, Wang M-Y, Su C-T, Yang T-T, Huang C-J, et al. Psychometric Evaluation of the Chinese Version of the Pittsburgh Sleep Quality Index (CPSQI) in Primary Insomnia and Control Subjects. Qual Life Res. 2005;14:1943-52.

21. Suleiman KH, Yates BC, Berger AM, Pozehl B, Meza J. Translating the Pittsburgh sleep quality index into Arabic. West J Nurs Res. 2010;32:250-268.

22. Al Maqbali M, Dunwoody L, Rankin J, Hacker E, Hughes C, Gracey J. Psychometric properties and cultural adaptation of sleep disturbance measures in Arabic-speaking populations: A systematic review. J Sleep Res. 2020;29:e12877.

23. Ho RTH, Fong TCT. Factor structure of the Chinese version of the Pittsburgh Sleep Quality Index in breast cancer patients. Sleep Med. 2014;15:565-9.

24. Otte JL, Rand KL, Carpenter JS, Russell KM, Champion VL. Factor Analysis of the Pittsburgh Sleep Quality Index in Breast Cancer Survivors. J Pain Symptom Manage. 2013;45:620-7.

25. Nunnally JC. Psychometric Theory. 3rd ed. New York: McGraw-Hill; 1994.

26. Lim CR, Harris K, Dawson J, Beard DJ, Fitzpatrick R, Price AJ. Floor and ceiling effects in the OHS: an analysis of the NHS PROMs data set. BMJ Open. 2015;5:e007765.

27. Fontes F, Gonçalves M, Maia S, Pereira S, Severo M, Lunet N. Reliability and validity of the Pittsburgh Sleep Quality Index in breast cancer patients. Support Care Cancer. 2017;25:3059-66. 
28. Hair JF, Black WC, Babin BJ, Anderson RE. Multivariate Data Analysis: Pearson New International Edition. 7th ed. London: Pearson Higher Ed; 2014.

29. George GC, Iwuanyanwu EC, Anderson KO, Yusuf A, Zinner RG, Piha-Paul SA, et al. Sleep quality and its association with fatigue, symptom burden, and mood in patients with advanced cancer in a clinic for early-phase oncology clinical trials: Sleep, Fatigue, and Mood in Cancer. Cancer. 2016;122:3401-9.

30. Wu LM, Amidi A, Valdimarsdottir H, Ancoli-Israel S, Liu L, Winkel G, et al. The Effect of Systematic Light Exposure on Sleep in a Mixed Group of Fatigued Cancer Survivors. J Clin Sleep Med. 2018;14:31-9.

31. Tzeng JI, Fu Y-W, Lin C-C. Validity and reliability of the Taiwanese version of the Pittsburgh Sleep Quality Index in cancer patients. Int J Nurs Stud. 2012;49:102-8.

32. Yennurajalingam S, Tayjasanant S, Balachandran D, Padhye NS, Williams JL, Liu DD, et al. Association between Daytime Activity, Fatigue, Sleep, Anxiety, Depression, and Symptom Burden in Advanced Cancer Patients: A Preliminary Report. J Palliat Med. 2016;19:849-56.

33. Palesh O, Haitz K, Lévi F, Bjarnason GA, Deguzman C, Igbal A, et al. Relationship Between Subjective and Actigraphy-Measured Sleep in 237 Patients with Metastatic Colorectal Cancer. Qual Life Res. 2017;26:2783-91.

34. Cole JC, Motivala SJ, Buysse DJ, Oxman MN, Levin MJ, Irwin MR. Validation of a 3-factor scoring model for the Pittsburgh sleep quality index in older adults. Sleep. 2006;29:112-6.

35. Chong AML, Cheung C. Factor structure of a Cantonese-version Pittsburgh Sleep Quality Index. Sleep Biol Rhythms. 2012;10:118-25.

36. Bastien CH, VallieÁres A, Morin CM. Validation of the Insomnia Severity Index as an outcome measure for insomnia research. Sleep Med. 2001;2:297-307. 
Table 1: Demographic and clinical characteristic of participants $(\mathrm{N}=369)$ :

\begin{tabular}{|l|c|c|}
\hline \multicolumn{3}{|l|}{ Demographic Characteristic } \\
\hline & $\mathrm{n}$ & $\%$ \\
\hline Gender & & \\
\hline Male & 124 & 33.6 \\
\hline Female & 245 & 66.4 \\
\hline Age & & \\
\hline $18-30$ & 36 & 9.8 \\
\hline $31-40$ & 84 & 22.8 \\
\hline $41-50$ & 95 & 25.7 \\
\hline $51-60$ & 76 & 20.6 \\
\hline More than 60 & 78 & 21.1 \\
\hline Marital Status & & \\
\hline Married & 273 & 74 \\
\hline Single & 40 & 10.8 \\
\hline Divorced/Separated/widowed & 56 & 15.2 \\
\hline Education Level & & \\
\hline None & 75 & 20.3 \\
\hline Basic Education & 89 & 24.1 \\
\hline Secondary Education & 104 & 28.2 \\
\hline Degree & 101 & 27.4 \\
\hline Employment Stats & & \\
\hline Employed & 125 & 33.9 \\
\hline Retired & 71 & 19.2 \\
\hline Unemployed & 173 & 46.9 \\
\hline
\end{tabular}

\begin{tabular}{|l|c|c|}
\multicolumn{3}{|c|}{ Clinical Characteristic } \\
\hline Cancer Site & $\mathrm{n}$ & $\%$ \\
\hline Breast & 139 & 37.7 \\
\hline Colorectal & 54 & 14.6 \\
\hline Stomach & 18 & 4.9 \\
\hline Others & 29 & 7.9 \\
\hline Lung & 20 & 5.4 \\
\hline Gastrointestinal & 19 & 5.1 \\
\hline Brain & 19 & 5.1 \\
\hline lymphoma & 20 & 5.4 \\
\hline Gynaecological & 24 & 6.5 \\
\hline Urinary & 27 & 7.3 \\
\hline Stage & & \\
\hline One & 34 & 9.2 \\
\hline Two & 145 & 39.3 \\
\hline Three & 107 & 29 \\
\hline Four & 72 & 19.5 \\
\hline Unspecified & 11 & 3 \\
\hline Month Since Diagnosis & & \\
\hline < 12 months & 157 & 42.5 \\
\hline 12-24 months & 127 & 34.4 \\
\hline 25-36 months & 52 & 14.1 \\
\hline$>$ 36 months & 33 & 8.9 \\
\hline $\begin{array}{l}\text { Type of Treatment } \\
\text { Finished }\end{array}$ & & \\
\hline Chemo and Radio & 234 & 63.4 \\
\hline Chemotherapy & 122 & 33.1 \\
\hline Radiotherapy & 13 & 3.5 \\
\hline Comorbidities & 193 & 52.3 \\
\hline None & 8 & 2.2 \\
\hline Asthma & 13 & 3.5 \\
\hline Anemia & 21 & 5.7 \\
\hline Diabetes & 61 & 16.5 \\
\hline $\begin{array}{l}\text { Hypertensive/ Heart } \\
\text { Failure }\end{array}$ & 60 & 16.3 \\
\hline Diabetes/Heart diseases & 3.5 \\
\hline Others & & \\
\hline
\end{tabular}


Table 1: Internal consistency. Cronbach's $\alpha$ and ceiling-floor effect for PSQI component and total score (N=369):

\begin{tabular}{|c|c|c|c|c|c|c|c|c|}
\hline \multirow{2}{*}{ Component } & \multirow{2}{*}{$\begin{array}{l}\text { Score } \\
\text { Range }\end{array}$} & \multicolumn{2}{|c|}{ Scores } & \multirow{2}{*}{$\begin{array}{c}\text { Ceiling } \\
\text { effect } \\
(\%)\end{array}$} & \multirow{2}{*}{$\begin{array}{c}\text { Floor } \\
\text { effect } \\
(\%)\end{array}$} & \multirow{2}{*}{$\begin{array}{l}\text { Corrected } \\
\text { Item-Total } \\
\text { Correlation }\end{array}$} & \multirow{2}{*}{$\begin{array}{l}\text { Cronbach's } \\
\text { Alpha if } \\
\text { Item } \\
\text { Deleted }\end{array}$} & \multirow{2}{*}{$\begin{array}{l}\text { Cronbach's } \\
\text { Alpha Original } \\
\text { Version }\end{array}$} \\
\hline & & Mean & SD & & & & & \\
\hline 1. Subjective sleep quality & $0-3$ & 1.31 & 0.96 & $21.7 \%$ & $13.8 \%$ & 0.62 & 0.72 & $0.83^{\mathrm{a}}$ \\
\hline 2. Sleep latency & $0-3$ & 1.81 & 0.91 & $25.5 \%$ & $8.4 \%$ & 0.53 & 0.74 & $0.72^{\mathrm{a}}$ \\
\hline 3. Sleep duration & $0-3$ & 1.15 & 0.83 & $19.8 \%$ & $8.4 \%$ & 0.46 & 0.75 & $0.80^{\mathrm{a}}$ \\
\hline 4. Habitual sleep efficiency & $0-3$ & 0.96 & 1.07 & $46.6 \%$ & $12.7 \%$ & 0.41 & 0.77 & $0.85^{\mathrm{a}}$ \\
\hline 5. Sleep disturbances & $0-3$ & 1.66 & 0.66 & $9.8 \%$ & $0.5 \%$ & 0.38 & 0.77 & $0.46^{\mathrm{a}}$ \\
\hline 6. Use of sleep medication & $0-3$ & 0.95 & 1.05 & $11.9 \%$ & $45.8 \%$ & 0.53 & 0.74 & $0.62^{\mathrm{a}}$ \\
\hline 7. Daytime dysfunction & $0-3$ & 1.37 & 0.92 & $12.2 \%$ & $18.2 \%$ & 0.55 & 0.73 & $0.63^{\mathrm{a}}$ \\
\hline Global Score & $0-21$ & 9.22 & 4.21 & 0 & 0 & & 0.77 & $0.83^{\mathrm{a}}$ \\
\hline
\end{tabular}


Table 3: Global PSQI score according to the patient demographic and clinical characteristics:

\begin{tabular}{|c|c|c|c|c|c|}
\hline & $\mathbf{n}$ & Mean & SD & $F$ & $\boldsymbol{P}$ \\
\hline Gender & & & & .616 & .538 \\
\hline Male & 124 & 9.03 & 4.15 & & \\
\hline Female & 245 & 9.32 & 4.25 & & \\
\hline Cancer Site & & & & 5.091 & $<.001$ \\
\hline Breast & 139 & 8.34 & 4.13 & & \\
\hline Colorectal & 54 & 9.19 & 3.62 & & \\
\hline Stomach & 18 & 9.22 & 2.92 & & \\
\hline Others & 29 & 7.86 & 4.16 & & \\
\hline Lung & 20 & 12.95 & 3.53 & & \\
\hline Gastrointestinal & 19 & 12.05 & 3.96 & & \\
\hline Brain & 19 & 11.84 & 4.89 & & \\
\hline lymphoma & 20 & 9.50 & 4.75 & & \\
\hline Gynaecological & 24 & 9.25 & 3.40 & & \\
\hline Urinary & 27 & 8.48 & 4.23 & & \\
\hline Stage of Disease & & & & 3.679 & .006 \\
\hline I & 34 & 8.32 & 4.52 & & \\
\hline II & 145 & 8.61 & 3.98 & & \\
\hline III & 107 & 9.45 & 4.07 & & \\
\hline IV & 72 & 10.69 & 4.29 & & \\
\hline Unspecified & 11 & 8.27 & 5.14 & & \\
\hline Comorbidities & & & & 5.139 & $<.001$ \\
\hline No & 193 & 8.18 & 4.03 & & \\
\hline Yes & 176 & 10.36 & 4.13 & & \\
\hline
\end{tabular}




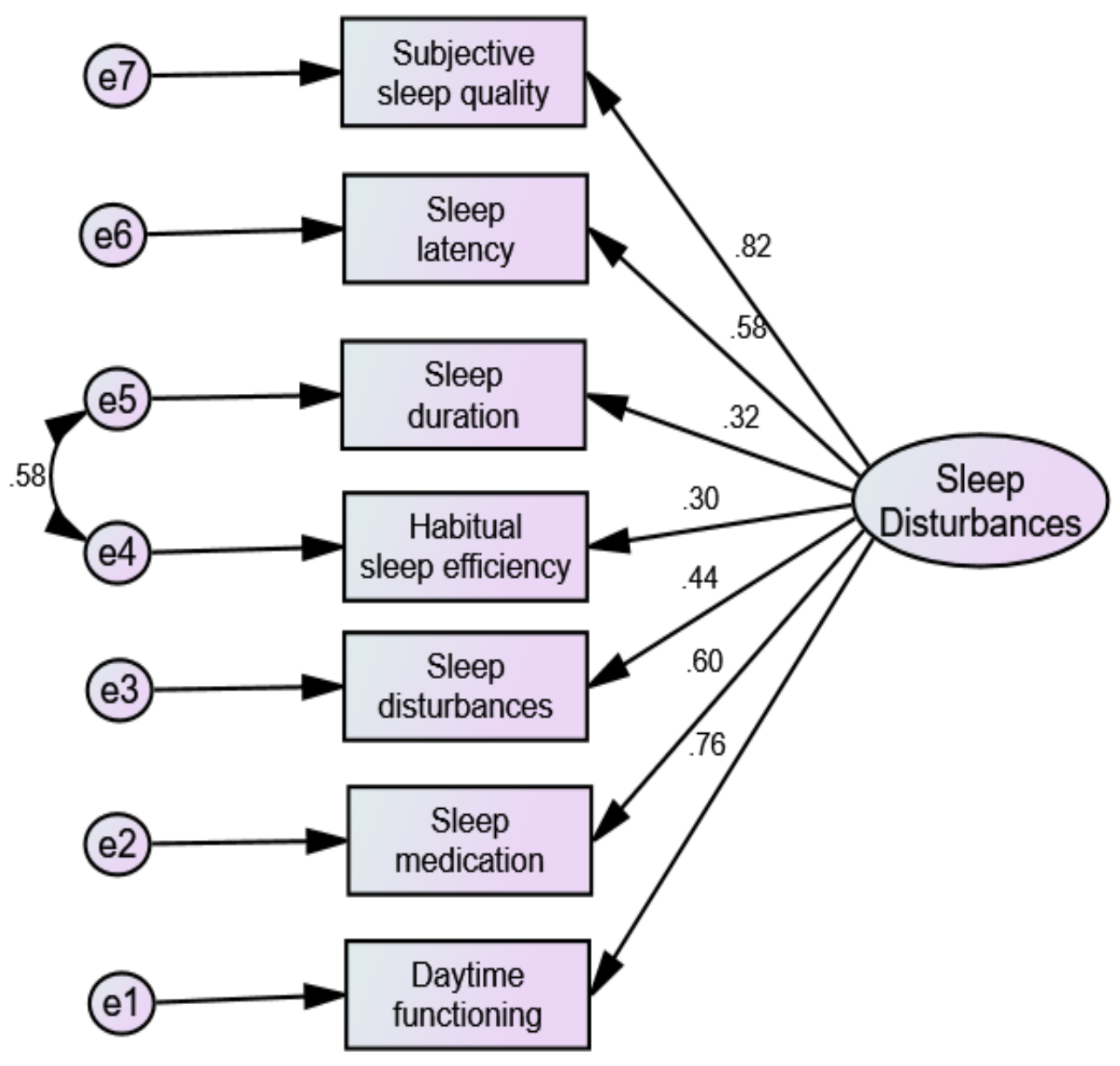

Figure 1: Confirmatory factor analysis for the refined one-factor model of PSQI Arabic cancer patients $(\mathrm{n}=369)$ with correlation between e4 and e5. $\chi^{2}(\mathrm{df}=13)=35.18 ; P$ value <.001; $\chi^{2} / \mathrm{df}=2.7$; Goodness of Fit Index $(\mathrm{GFI})=0.97$; adjusted goodness of fit index $(\mathrm{AGFI})=0.94$; Comparative Fit Index $(\mathrm{CFI})=0.97$, Tucker-Lewis Index $(\mathrm{TLI})=.95$; Root Mean Square Error of Approximation (RMSEA) $=0.06$. 


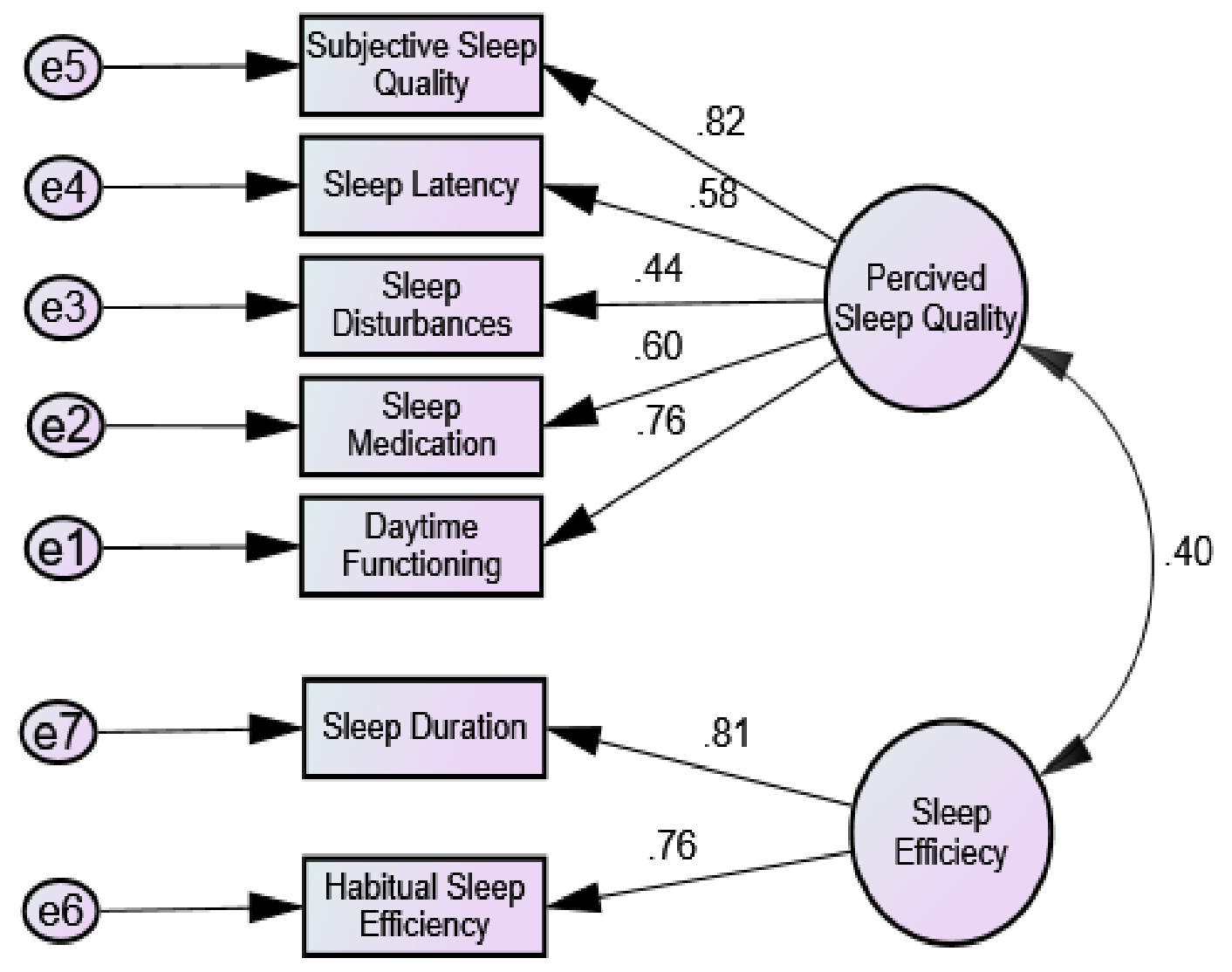

Figure 2: Confirmatory factor analysis for the two-factor model of PSQI Arabic cancer patients $(\mathrm{n}=369)$ with correlation between e4 and e5. $\chi^{2}(\mathrm{df}=13)=35.18 ; P$ value $<.001 ; \chi^{2} / \mathrm{df}=$ 2.7; Goodness of Fit Index $(\mathrm{GFI})=0.97$; adjusted goodness of fit index (AGFI) $=0.94$;

Comparative Fit Index $(\mathrm{CFI})=0.97$, Tucker-Lewis Index $(\mathrm{TLI})=.95$; Root Mean Square Error of Approximation $($ RMSEA $)=0.06$. 